\title{
The application of warm mix asphalt technology in China: a review
}

\author{
Jiantong Zhang ${ }^{1, a}$, Lihua $\mathrm{Xu}^{2}$,Lusheng $\mathrm{Lin}^{3}$ and Sumei Liu ${ }^{4}$ \\ ${ }^{1}$ School of Civil, Wuhan University, NO.299 BAYI Road, Wuchang District, Wuhan, 430072, China; NO. 213 \\ Qinglinzhong Road, Bureau of construction works longgang district, Shenzhen, 518172, China \\ ${ }^{2}$ School of Civil, Wuhan University, NO.299 BAYI Road, Wuchang District, Wuhan, 430072, China \\ Email:xulihuad@163.com \\ ${ }^{3}$ NO. 213 Qinglinzhong Road, Bureau of construction works longgang district, Shenzhen, 518172, China \\ Email: lushenglin@163.com \\ ${ }^{4}$ School of Civil, Wuhan University, NO.299 BAYI Road, Wuchang District, Wuhan, 430072, China \\ Email:1225101791@qq.com
}

\begin{abstract}
Increasing emission of greenhouse gases is an environmental issue, and it is a great concern to curb this problem from further harm to the environment. With increasing interest in the use of warm mix asphalt (WMA) in the paving industry, more studies in this field for improvement of WMA properties seem to be necessary. WMA technology, recently developed in Europe, is gaining strong interest in the China. WMA has various benefits such as, reduction of asphalt binder temperature, reduction in energy consumption and less air pollution. It reduces short-term aging, compacting effort and decreases temperature drop during transportation. This paper reviews that the warm-mix asphalt have the potential of improving pavement performance, efficiency and environmental stewardship. Overall, warm-mix asphalt provides substantial sustainability benefits similar to or, in some cases, better than conventional hot-mix asphalt.
\end{abstract}

Keywords: WMA, pavement sustainability, asphalt additives, reduced emissions.

\section{Introduction}

Global concerns over the increasing damage to the environment from greenhouse gas emissions has created greater awareness, within the past two decades, for sustainable development practices in all spheres of human endeavor including the road construction industry [1]. Production of the mix at high temperatures is a source of concern as it requires high energy use, results in binder aging in the hotmix plant and the generation of greenhouse gases. To address these concerns, the asphalt industry has developed warm-mix asphalt technologies that enable the production of asphalt mixes at temperatures that are $20^{\circ} \mathrm{C}-40^{\circ} \mathrm{C}$ lower than conventional HMA production temperatures.

WMA technologies were pioneered in Europe [2]. Many countries are adopting WMA technologies due to their advantages in sustainability. The growing acceptance of WMA is based on

${ }^{a}$ Corresponding author : tongtong01@126.com 
confirmation of its economic, environmental and performance benefits relative to conventional HMA, and it is anticipated that WMA will soon become the standard practice within the industry [3-5].

The motivation for WMA development was derived from the Kyoto Protocol which emphasized a worldwide concerted effort to reduce greenhouse gas emissions into the atmosphere. More recently, though, additional impetus has come from the United Nations Climate Summit held on September 23, 2014 in New York, at which world leaders and several organizations announced strong commitments to cut greenhouse gas emissions [6]. This paper presents a review of literature on the technologies, applications and social benefits with warm mix asphalt in the asphalt pavement.

\section{Review of warm mix asphalt technology}

In 1995, Shell and Kolo-veidekke jointly developed a warm mix asphalt technology, and the following year conducted a field test using this technology [7-8]. In the development and use of early, Shell and Kolo-veidekke use soft asphalt and emulsified asphalt to produce warm mix asphalt, this WMA can be the same as the hot mix asphalt mixture in performance, but the cost of production is higher than the HMA by $20 \%$. In order to reduce the cost of production and improve the performance of WMA, shell and Kolo-veidekke use foamed asphalt and soft asphalt to produce WMA in 1998. And then the WMA of field tests were conducted. And the comparison of field experiment between WMA and HMA was made. After a long period of observation, it found that the road performance of WMA is good. In 2000, the concept of WMA was put forward for the first time by Harrison and Christodulaki at the 1st International World of Asphalt Pavements Conference. In the same year, the WMA was large-scale introduced at the 2nd Eurasphalt \& Eurobitume Congress [8]. Subsequently, WMA have been a large number of applications in Japan and Europe and other places. At present, the usage of WMA is increasing year by year, and WMA has become a hot research topic in the international research of asphalt pavement [9-15].

In 2002, the WMA technology was adopted by the United States. And the first warm asphalt pavement was constructed in 2004. The Warm Mix Asphalt Technical Working Group was set up to systematically evaluate and guide warm mix technology, and to promote the application and popularization of warm mix technology in 2005. In order to formulate the design of mix proportion and pavement performance test specifications for warm mix asphalt, the project of NCHRP 09-43 was conducted [16]. In order to provide a guide for the construction of warm mix asphalt mixture, NCHRP 09-47 project had been completed [17]. Warm mix asphalt material has been widely studied and applied in the United States, there are hundreds of warm mix asphalt mixture construction or pilot projects in the United States.

In China, WMA technology was started in 2005. In 2005, the Evotherm warm mix technology was used to build the first warm asphalt pavement in China. In 2006, the Evotherm warm mix technology was used to build the world's first SMA pavement with modified asphalt. In 2008, the world's first rubber warm mix asphalt pavement was built with Evotherm warm mix technology. Since 2006, the Evotherm warm mix asphalt technology has been widely spread in China, especially in Beijing and Shanghai successfully implemented nearly 20 projects. Also, Sasobit warm mix technology has been widely used, in China. At present, dozens of projects constructed with WMA technology have been the successful implementation, including Shanghai Donghai Avenue, Chongqing lijiatuo bridge, Shanghai Lupu Bridge, and Shandong Yellow River Bridge and so on.

\section{Advantages of WMA}

There are numerous benefits of WMA identified by several researchers. According to the development of warm mix technology[18-22], the advantage of WMA is mainly reflected in the following aspects:

- significantly lower production and placement temperatures, which can save more than $30 \%$ of the energy consumption. 
- decreased the harmful gases and dust emissions from mixing plant and during placement. improved working conditions for plant/paving crew; less aging of binder during plant mixing and placement, thus improving longevity of

pavement service life;

- extended paving season (i.e., paving during cooler weather);

- significantly improve tunnel construction, and improve construction of visibility.

\section{Engineering application}

Studies [23-25] have shown that WMA performs equally or possibly better than HMA and that both materials have similar versatility. WMA has been 1) used in dense-graded, stone matrix, mastic, and open-graded friction-course mixes; 2) used with polymer-modified binders; 3) placed in pavements with traffic expected to exceed 30 million 18-kip-equivalent single-axle loads and in a range of layer thicknesses; and 4) paved at bus stops, on airfields, and on port facilities [26]. In all these applications, WMA exhibited similar or better performance, including improved compaction, similar stiffness and rutting resistance, improved resistance to fatigue and thermal cracking, similar or less moisture damage and greater durability compared with HMA [26].

\section{Conclusion}

Warm-mix asphalt is a new asphalt technology, which saves energy and cost. WMA reduces the temperature of asphalt binder during mixing and laying stages and has the benefits of economic, environmental, performance and social. So, WMA as a sustainable pavement is good for environment with a drop of global warming and decreasing emissions of greenhouse gases in the atmosphere.

\section{References}

1. Tutu, K.A. and Tuffour, Y.A. (2016) Warm-Mix Asphalt and Pavement Sustainability: A Review. Open Journal of Civil Engineering, 6, 84-93.

2. Jones, W. (2004) Warm Mix Asphalt Pavements: Technology of the Future? Asphalt: The Magazine of the Asphalt Institute, 19, 8-11.

3. Nicholls, J.C. and James, D. (2013) Literature Review of Lower Temperature Asphalt Systems. Proceedings of the Institution of Civil Engineers-Construction Materials, 166, 276-285. http://dx.doi.org/10. 1680/coma.11.00051

4. Croteau, J.-M. and Tessier, B. (2008) Warm Mix Asphalt Paving Technologies: A Road Builder's Perspective.

http://www.colascanada.ca/uploads/colascanada/File/expertise/WarmMixAsphaltPavingTechnol ogies.pdf

5. Alderson, A. (2010) Review of the Environmental Aspects of Warm Mix Asphalt. Austroads Publication No. APT163/ 10. www.austroads.com.au

6. UN Press Release (2014) September 2014 Climate Summit Press Release. http://www.un.org/climatechange/summit/wp-content/uploads/sites/2/2014/05/Climate-Summitmain_FINAL-PR.pdf

7. Harrison T, Christodulaki L. Innovative processes in asphalt production and application strengthening asphalt's position in helping to build a better world. First International Conference: World of Asphalt Pavements, Sydney, 2000.

8. Advisory note 17 -Warm Mix Asphalt a state of the art review [EB/OL].Australian Asphalt Pavement Association (AAPA). http://www.aapa.san.au/docs/no17.pdf,2000.

9. Prowell B D, Hurley G C, Crews E. Field Performance of Warm-Mix Asphalt at National Center for Asphalt Technology Test Track[J]. Transportation Research Record Journal of the Transportation Research Board, 2007, 1998(1):96-102. 
10. Lee S J, Amirkhanian S N, Park N W, et al. Characterization of warm mix asphalt binders containing artificially long-term aged binders[J]. Construction \& Building Materials, 2009, 23(6):2371-2379.

11. Mallick R B, Kandhal P S, Bradbury R L. Using Warm-Mix Asphalt Technology to Incorporate High Percentage of Reclaimed Asphalt Pavement Material in Asphalt Mixtures[J]. Transportation Research Record Journal of the Transportation Research Board, 2008, 2051(-1):71-79.

12. Middleton B. Evaluation of Warm-Mix Asphalt Produced with the Double Barrel Green Process[J]. Transportation Research Record Journal of the Transportation Research Board, 2009, 2126(2126):19-26.

13. Haggag M M, Mogawer W S, Bonaquist R. Fatigue Evaluation of Warm-Mix Asphalt Mixtures[J]. Transportation Research Record Journal of the Transportation Research Board, 2011, 2208(-1):26-32.

14. Mogawer W S, Austerman A J, Bahia H U. Evaluating the Effect of Warm-Mix Asphalt Technologies on Moisture Characteristics of Asphalt Binders and Mixtures[J]. Transportation Research Record Journal of the Transportation Research Board, 2011, 2209(-1):52-60.

15. Kheiry P T, Qiu T, Solaimanian M. Characterization of Warm Mix Asphalt through Resonant Column Testing[J]. Journal of Materials in Civil Engineering, 2015, 27(10).

16. Bonaquist R F. Mix design practices for warm mix asphalt[M]. Transportation Research Board, 2011.

17. Lee J J, Yang S L, Kwon S A, et al. A Study of Performance Evaluation of Warm Asphalt Binder Properties using LEADCAP (R) additive[J]. International Journal of Highway Engineering, 2011, 13(2): 1-8.

18. Zaumanis, M. and V. Haritonovs. 2010. Research on properties of warm mix asphalt. Scientific Proceedings of Riga Technical

19. Rubio, M. C., Martinez, G., Baena, L., and Moreno, F. 2012. Warm mix asphalt: an overview. Journal of Cleaner Production. 24: 76-84.

20. Prowell B D, Hurley G C, Frank B. Warm-mix asphalt: Best practices[M]. Lanham, Md, USA: National Asphalt Pavement Association, 2011.

21. Bueche N. Warm asphalt bituminous mixtures with regards to energy, emissions and performance[J]. Young Researchers Seminer (YRS), Torino, 2009.

22. Wang H, Dang Z, You Z, et al. Effect of warm mixture asphalt (WMA) additives on high failure temperature properties for crumb rubber modified (CRM) binders[J]. Construction and Building Materials, 2012, 35: 281-288.

23. National Asphalt Paving Association (NAPA) (2009). Black and Green: Sustainable Asphalt, Now and Tomorrow. Special Report Number 200. National Asphalt Paving Association, Lanham. http://www.hotmix.org/images/stories/sustainability_report_2009.pdf.

24. European Asphalt Pavement Association (EAPA) (2010). EAPA Position Paper on the Use of Warm Mix Asphalt.

http://www.eapa.org/usr_img/position_paper/the_use_of_warm_mix_asphalt_january_2010.pdf

25. Croteau J M, Tessier B. Warm mix asphalt paving technologies: a road builder's perspective[C]//Annual Conference of the Transportation Association of Canada, Toronto. 2008.

26. D’Angelo, J., Harm, E., Bartoszek, J., Baumgardner, G., et al. (2008). Warm-Mix Asphalt: European Practice. International Technology Scanning Program, Federal Highway Administration. Report No. FHWA-PL-08-007. www.international.fhwa. dot.gov. 